\title{
Meaning in the mind within the sociocultural commitment of Cognitive Linguistics
}

\author{
Nikolay N. Boldyrev ${ }^{1}$ \\ Derzhavin Tambov State University, Tambov \\ Olga G. Dubrovskaya \\ Tyumen State University, Tyumen \\ Irina Tolmacheva \\ Derzhavin Tambov State University, Tambov
}

\begin{abstract}
The article reviews the problem of meaning construction and language use in the field of sociocultural cognitive semantics, focusing on meaning as a dynamic experience construction process represented by virtue of language within multiple networks of human knowledge. After outlining the core theoretical assumptions, the article examines the empirical evidence on the processes that underlie the generation of meaning. The paper presents five outcomes for both usage-based theory and empirical linguistic methodology. In reviewing the evidence, we highlight issues of alternative potential explanations as well as remaining areas for future research. The approach establishes new findings and authentic contributions to cognitive linguistics.
\end{abstract}

Keywords: Sociocultural Cognitive Semantics, contexts of knowledge, metaconcepts, context-ofsociocultural-knowledge-oriented construal, meaning in the mind

\section{Introduction}

The idea that meaning is inside the mind of the individual is not new and one that

Corresponding author - Derzhavin Tambov State University, 408 off., 151 I Sovetskaya Str., Tambov 392000, Russian Federation.

Email: boldyrev@tsu.tmb.ru 
has always been obvious but has not been given a clear explanatory format. An important step towards the human perspective of meaning was the growing evidence for the conception of language as both a psychological and cultural phenomenon (see, for example, Geeraerts, 2010; Harder, 2010, and others). In many ways, the perspective accords with the assumptions that: a) human cognition is embodied, i.e. deeply dependent upon features of the physical body; b) all thought is essentially metaphorical; c) basic cognitive processes are universal and encompass attention, memory, learning, inferential capacities, etc.; d) cognition is culturally embedded, i.e. influenced by practical activity that is culturally constrained and historically developing (see, for instance, Lakoff \& Johnson, 1999; Langacker, 2000; Tomasello, 1999; Vygotsky, 1986).

Nowadays, the idea that human cognition is inherently culture-specific is one that pervades much scholarship. In reference to Holland and Quinn's monograph, D. Geeraerts claims that,

\section{social turn, it should be pointed out, is not a complete novelty in the history of Cognitive Linguistics, given that, for instance, the notion of 'cultural model' played a significant role in the emergence of the new framework. (Geeraerts, 2016, p. 528)}

Basically, recent work in Cognitive Linguistics theory generally, and in Cognitive Semantics more specifically, has attempted to challenge the generative paradigm with its focus on an autonomous formal grammar (e.g. Evans \& Green, 2006; Lakoff \& Johnson, 1999; Langacker, 2000).

Recent publications have advocated a usage-based approach for analyzing language; interrelation of cognitive abilities, language as a cognitive ability included; and dictionary and encyclopaedic information in meaning (e.g., Boldyrev, 2015; Demyankov, 1994; Hart, 2010; Kubryakova, 2004). Although a genuine "social turn" of cognitive linguistics has always been recognized (e.g., Croft, 2009; Geeraerts, 2010; Harder, 2010; Tomasello, 1999), it has not been fully elaborated to reveal the mechanisms of meaning-making and language use. In our previous work (Boldyrev \& Dubrovskaya, 2016) we integrated the cognitive and sociocultural perspectives into a single theoretical framework - Sociocultural Commitment of Cognitive Linguistics - to investigate the mechanisms that underlie sociocultural discourse specificity construction and meaning-making process.

The Sociocultural Commitment in our view is to be a comprehensive framework of language use that covers the whole spectrum from how discourse is constructed, what makes representatives of different sociocultures understand each other, what part language plays in negotiation of identities. It claims that the content of the human mind is experiential as well as psychological and provides Sociocultural 
Cognitive Semantics with an essential human dimension and attributes the dimension to meaning as well.

In this article, we will focus on two perspectives. The first corresponds to the cognitive sphere which involves everything that is internal to human mental life including the ability to speak languages, to perceive the world, to conceptualize and categorize objects, events, etc. It is universal and characteristic of every human being, not suffering from some particular mental disease. The second direction, internal as well, is involved with HOW contexts are embedded in our cognition for language and meaning, HOW human beings interpret the world through the language they speak in communicative settings and HOW patterns of behavior they acquire as members of sociocultures influence their discourse construction. This perspective is culture-specific, for it depends on the individual knowledge about the society and culture a participant represents.

On the whole, the topic that is raised in the article addresses: i) the semantic structure of discourse as language use irrespective of its length, genre or modality, as well as the channels of information/communication and ii) the interrelationships of conceptual structures - the metaconcepts - that group vast amounts of knowledge into large structuring systems associated with the experiences participants have as sociocultural agents. So, the aim of the article is to ascertain the integrated system of conceptual structuring in discourse (language use) and pursue an approach to the field of Sociocultural Cognitive Semantics that addresses the concerns of linguistically structured knowledge and experience of speakers as representatives of societies and cultures. First, the approach examines types of knowledge in terms of contexts of collective knowledge and contexts of sociocultural knowledge that underlie language use and play a crucial part in the process of meaning-making. Second, it aims both to help account for mismatches in interactions between language speakers. In the long run, its aim is to integrate the linguistic and sociocultural perspectives on cognitive organization in a unified understanding of human conceptual structure that is verbally represented in encounters.

More specifically, the aim of this work is to present the basic results of a research project that has recently been carried out and is likely to encourage interdisciplinary and methodologically rigorous research in the fields of Discourse Studies, Communication and Cognitive Sciences in general. Central to this area of research are the issues related to significant questions about the thought process behind the understanding of language; the cognitive faculties that are involved in the communication process; universal conceptual structures that are available to speakers of languages through which they construct discourses and which regulate language use. These issues follow D. Geeraerts in arguing that, 
if the primary function of language involves knowledge and communication, then meaning in the broadest sense must be the prime focus of linguistic attention. (Geeraerts, 2016, p. 531)

Section 2 reviews the key theoretical perspectives and ideas that are relevant for the study. Section 3 provides empirical evidence drawn from a variety of sources with samples of on-line and off-line discourse that illustrate the efficacy and validity of the theoretical framework and prove its explanatory format. A concluding section outlines the areas of further inquiry.

\section{Review of the theoretical framework}

Language is neither distinct from mental content, nor is it altogether objective. As D. Geeraerts puts it,

language is studied not as if it were a separate and autonomous cognitive module, but as a reflection of general conceptual organization, categorization principles, processing mechanisms, and experimental and environmental influences (Geeraerts, 2016, p. 531)

with the Speaker as the central figure among them all.

In the article, we appeal to the idea that meanings which speakers generate in the process of language use depend upon the knowledge an individual acquires as a representative of a socioculture (compare to the well-known idea of meaning as "conditions of truth and falsity"). Two individuals may acquire different knowledge about one and the same object due to the knowledge of the external environment: a child holds the idea that water quenches thirst; a chemist constructs theoretical observations about water as a chemical compound which consists of two atoms of hydrogen bonded to one atom of oxygen.

In real communicative settings language speakers demonstrate their subjective views and preferences as to what language units to choose to create and maintain meanings and how to structure the information that has been acquired throughout life by speakers as representatives of various sociocultural backgrounds. Discourse as language use has a complex metaconceptual structure. It requires the activation of large amounts of sociocultural knowledge that needs to be instantiated by a language speaker. Since sociocultural knowledge is co-constructed and contextualized in everyday life, the primary research question is related to the idea how meaning is negotiated in discourse (language use) and what processes underlie its subjective and dynamic nature.

When we locate meaning in the mind, we believe that: a) meaning involves 
interpretation within contexts of knowledge a speaker possesses as a representative of a particular sociocultural background (compare to the well-known idea of context as "sensitivity of meaning") and b) meaning is what we apply to discourse through interpretation. One and the same linguistically coded thought or idea may have a multiplicity of interpretations depending on the contexts of knowledge: He turned red may mean "he is angry" or "he is embarrassed", or "he is a communist". So, meaning arises out of contexts of knowledge that, in turn, represent what speakers learnt about the world in the processes of conceptualization, categorization, and interpretation.

The fundamental basis of the "meaning-in-the-mind-within-the-socioculturalcommitment-of-cognitive-linguistics" perspective maintains the following insights:

1) Language use involves two types of context: context of collective knowledge and context of sociocultural knowledge. The first encompasses the overall knowledge that is embedded in language as it is shared by a particular speech community. The second is responsible for an individually grounded interpretation. Consider an example with the context of collective knowledge about sport as "an activity involving physical exertion and skill in which an individual or team competes against another for entertainment" (en.oxforddictionaries.com) and the contexts of sociocultural knowledge about sport as "a way to build character", as in (1) or "a waste of money", as in (2):

Running isn't a sport for pretty boys... It is about the sweat in your hair and the blisters on your feet. It is the frozen spit on your chin and the nausea in your gut. It is about throbbing calves and cramps at midnight that are strong enough to wake the dead (Paul Maurer)

(goodreads.com);

France international Paul Pogba would be 'a waste of money' if he were to cost Manchester United £100m (dailymail.co.uk).

2) The two contexts correlate by virtue of large amounts of knowledge that are instantiated in discourse by each language speaker. They are universal knowledge structures all people possess irrespective of their ethnicity, language group, nationality, or any other class distinction. They are metaconcepts that structure verbalized cognition: ROLE, VALUE, STEREOTYPE, NORM, TIME, SPACE, LANGUAGE PERFORMANCE. In our previous works, we argued that the metaconcepts ("meta" from the Greek language means "among", "beyond", "along with") are acquired by individuals throughout their life due to the roles they perform; qualities, meanings and stereotypes they ascribe to objects and events; norms and rules they violate or observe; the experience which comes from practice in an activity that, in turn, takes place within some particular space and time (Boldyrev \& Dubrovskaya, 2016). These 
metaconcepts reveal sociocultural discourse specificity: language speakers "fill them with" the knowledge they acquire as representatives of a particular society and culture. This contextual instantiation of discourse was referred to as 'the maxim of subjective discourse construction and interpretation' (Boldyrev \& Dubrovskaya, 2016) according to which the semantic content of discourse is structured from a viewpoint of its participants. Consider some examples:

Liza: You got no right to touch me (Shaw. Pygmalion. 1994, p. 25)

is structured by the metaconcept NORM which constitutes the conditions of how to treat women;

Higgins: Don't you know that a woman of that class looks a worn out drudge of fifty a year after she is married (Shaw. Pygmalion. 1994, p. 25);

We have all heard the adage that customers assume that by extension an unkempt bathroom must mean a disastrously unkempt kitchen (aaronallen.com)

are structured by the metaconcept STEREOTYPE (they $(4,5)$ are generalized beliefs);

(6)

Liza: That ain't proper writing, I can't read that (Shaw. Pygmalion. 1994, p. 15)

is structured by the metaconcept LANGUAGE PERFORMANCE which represents the "doing" with the language rather than "knowing" it (see Chomsky, 1986);

I want to be a lady in a flower shop stead of selling at the corner of Tottenham Court Road (Shaw. Pygmalion. 1994, p. 21)

is structured by the metaconcept VALUE as something worthy and important for the speaker.

3) The contextual instantiation of language use reveals three basic interpretive capacities of the mind: the capacity to select, to classify, and to evaluate objects, ideas, etc. For example: The selection of such features, as "equality", "freedom" in $(8,9)$ and the choice of 'the people', as in $(10,11)$ :

We are true to our creed when a little girl born into the bleakest poverty knows that she has the same chance to succeed as anybody else, because she is an American; she is free, and she is equal, not just in the eyes of God but also in our own (obamawhitehouse.archives.gov); With common effort and common purpose, with passion and dedication, let us answer the call of history and carry into an uncertain 
future that precious light of freedom (obamawhitehouse.archives.gov); That all changes starting right here and right now, because this moment is your moment. It belongs to you (Trump's inauguration speech; cnbc.com);

The forgotten men and women of our country will be forgotten no longer (cnbc.com).

The classification of the government and the citizens of the country in one group, as in $(12,13)$ and in different groups, as in $(14,15)$ :

$$
\begin{aligned}
& \text { We, the people, still believe that every citizen deserves a basic measure } \\
& \text { of security and dignity. We must make the hard choices to reduce the } \\
& \text { cost of health care and the size of our deficit } \\
& \text { (obamawhitehouse.archives.gov); } \\
& \text { We recognize that no matter how responsibly we live our lives, any one } \\
& \text { of us at any time may face a job loss, or a sudden illness, or a home } \\
& \text { swept away in a terrible storm (obamawhitehouse.archives.gov); } \\
& \text { Today's ceremony, however, has a very special meaning because today } \\
& \text { we are not merely transferring power from one administration to } \\
& \text { another or from one party to another, but we are transferring power } \\
& \text { from Washington, D.C., and giving it back to you, the people (cnbc.com); } \\
& \text { The establishment protected itself, but not the citizens of our country } \\
& \text { (cnbc.com). }
\end{aligned}
$$

The evaluation of the country as 'a superpower' in (16) and 'acting in accord with divine or moral law', as in (17):

$$
\begin{aligned}
& \text { Our brave men and women in uniform, tempered by the flames of } \\
& \text { battle, are unmatched in skill and courage; }<\text {... }>\text { And we will renew } \\
& \text { those institutions that extend our capacity to manage crisis abroad, for } \\
& \text { no one has a greater stake in a peaceful world than its most powerful } \\
& \text { nation; <... Together, we resolved that a great nation must care for the } \\
& \text { vulnerable, and protect its people from life's worst hazards and } \\
& \text { misfortune (obamawhitehouse.archives.gov); } \\
& <\ldots \text {... These are just reasonable demands of righteous people and a } \\
& \text { righteous public (cnbc.com). }
\end{aligned}
$$

4) Selection, classification and evaluation provide the universal metaconcepts with 'individual contents', which account for a variety of discourses on one and the same topic by different people as representatives of individual sociocultural backgrounds. Mind is not only part of nature: the mind is 'ensociocultured' as well as embodied (comp.: Philosophy in the flesh: The embodied mind and its challenge to western thought, by G. Lakoff \& M. Johnson, 1999). Put another way, cognition is socioculturally embedded. It means that the purpose of our cognitive mechanisms is 
to provide a representation of the reality as it is seen through the lens of our knowledge that we acquire as members of particular societies and cultures. The main construal operation in the process of sociocultural discourse construction is the construal of reality that is to be mediated, in large measure, by the context of sociocultural knowledge: context-of-sociocultural-knowledge-oriented construal. In the following discourse samples, the speakers are oriented to the context of sociocultural knowledge - their occupation as biologists and their professional activity underlying it $(18,19)$ :

$$
\begin{aligned}
& \text { It's no Nobel Prize, but Barack Obama has a new honor to brag about. } \\
& \text { Scientists have named a parasite after him - and there's no worming } \\
& \text { out of it. Meet Baracktrema obamai, a tiny parasitic flatworm that lives } \\
& \text { in turtles' blood. A new study officially names the two-inch-long, hair- } \\
& \text { thin creature after Obama. Thomas Platt, the newly retired biology } \\
& \text { professor at Saint Mary's College in Indiana who chose the name, says } \\
& \text { it's an honor, not an insult (breitbart.com); } \\
& \text { Meet 'Neopalpa donaldtrumpi' - the threatened moth named after } \\
& \text { Donald Trump. With its striking crown of yellow and piercing stare, this } \\
& \text { newly discovered moth could only have been named after one man. } \\
& \text { The moth is described for the first time by evolutionary biologist Dr } \\
& \text { Vazrick Nazari in the latest edition of the journal Zookeys <...> } \\
& \text { (telegraph.co.uk). }
\end{aligned}
$$

The majority of people, however, see Obama and Trump as the $44^{\text {th }}$ and $45^{\text {th }}$ presidents of the USA and the meanings they ascribe to the proper names are associated with the role of the elected officials.

5) Sociocultural discourse specificity is revealed via cognitive-discursive interpretant (CDI, for short) method of analysis as a research tool for analyzing sociocultural knowledge of discourse construction and meaning creation that underlie the perspective within which sociocultural discourse specificity is assumed to be a participant's interpretative procedure, a representation of the mind. The cognitivediscursive interpretant reflects the process of interpretation of the world and verbalizing its results in terms of selection, classification and evaluation that are activated in discourse construction (see above). For example, conventionally assumed knowledge that is encoded by the word world includes: "the earth, especially together with the life it supports; the universe; humankind considered as social beings; people as the public; a group of people with common pursuits; a way of life" [thefreedictionary.com]. Consider the following samples where the concept WORLD is represented by the word planet in (20), the word globe in (21) and world in (22) depending upon the meaning the speaker wants to create:

$$
\text { Energy conservation is vital for the future of the planet (LLA, 2003, p. }
$$




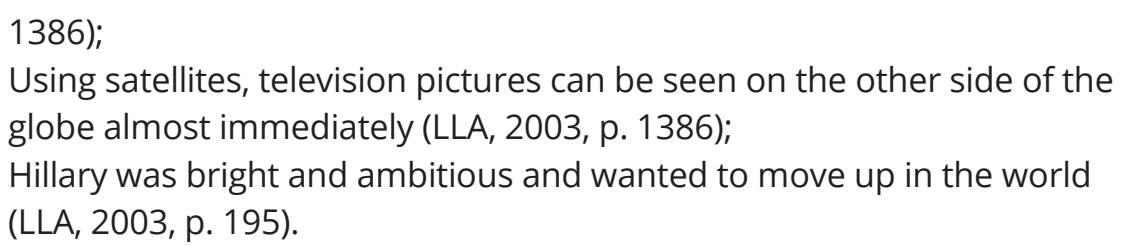

The CDI in (20) is activated by: i) the selection of the lexical concepts [ENERGY CONSERVATION], [PLANET] providing access to the domain PROBLEMS THAT AFFECT THE ENVIRONMENT; ii) categorizing the event in terms of the necessity to protect the environment and take care of it; iii) evaluating it as something very important. The CDI in (21) is activated by: i) the selection of the lexical concepts [SATELLITES], [TELEVISION PICTURES], [GLOBE] that give access to the domain GREAT DISTANCES AND AREAS; ii) putting the event into a category of advanced technology; iii) evaluating it as efficient. The CDI in (22) is activated by: i) the selection of the lexical concepts [BRIGHT], [AMBITIOUS], [GO UP IN THE WORLD] that give access to the domain SOCIAL CLASS; ii) putting the woman into a category of social climbers; iii) evaluating the event on the scale of a group the members of which want to move into a higher social class, and generally do so by becoming friendly with people who have more money or power than they do.

So, in this section, we have reviewed the theoretical groundings as a prelude to our further analysis of the data drawn from a variety of on-line and off-line sources.

\section{Empirical evidence}

Taking into account the theoretical framework, in this section we will focus our attention on the practical issues that especially become relevant in the process of meaning construction. As R. Langacker puts it on the cover of the monograph Cognitive Sociolinguistics. Social and cultural variation in cognition and language use (see Pütz, Robinson \& Reif, 2014),

since their very inception, Cognitive Linguistics and Cognitive Grammar
have explicitly recognized the fundamental role of social, cultural, and
interactive factors. Yet because this recognition has been more a matter of
principle than actual practice, the full potential for the mutual enrichment
of descriptive-theoretical concerns on the one hand, and sociolinguistic
investigation on the other hand, has only begun to be realized.

The starting point and the central insight in this section are to illustrate that: 1) conceptual systems of interactants might not correspond in their structure and content. Human beings attribute different characteristics to objects, due to individual life experiences and everyday practice; 2 ) minds of human beings are full of sets of concepts that constitute contexts of knowledge; 3) meanings are 
interpretations that reveal static and dynamic nature of cognition. Language is integrated with the human cognitive capacities at large. What the mind selects, classifies and evaluates as salient depends upon a number of factors (age, social status, territory, etc); 4) in discourse the metaconcepts are activated in clusters depending upon the meaning(s) the participant(s) want(s) to create. The following samples explore the challenges ensuing from the field of Sociocultural Cognitive Semantics.

As a rule, conceptual systems of interactants do not correspond structurally and depend upon the unique sociocultural experience of every person; situated knowledge included. In the following dialogue between a parent and a child one and the same domain BREAD is structured by two different context-of-socioculturalknowledge-oriented construals:

$$
\begin{aligned}
& \text { Child (sitting with his mom on the riverbank): Mommy, look! There is a } \\
& \text { duckling over there. Have you got some bread? } \\
& \text { Mom (deeply involved in reading the book): Could you eat without bread, } \\
& \text { honey? }
\end{aligned}
$$

The context of collective knowledge represented by the word bread activates the knowledge about BREAD as "a staple food made from flour; regarded necessary for sustaining life" [thefreedictionary.com]. As Langacker argues,

an expression's meaning is not just the conceptual content it evokes equally important is how that content is construed. (Langacker, 2008, p. 55)

The main lexical choice bread provides two different ways of framing a situation, giving rise to two context-of-sociocultural-knowledge-oriented construals: the mother activates the knowledge that babies are heavy-bread eaters and mothers are inclined to satisfy their hunger; the child associates BREAD with the habit of feeding birds.

The next examples illustrate that contents of conceptual systems that constitute contexts of knowledge might not correspond with different speakers. One and the same word-form is likely to activate non-similar ideas and create different meanings. Parenting, for instance, which activates the collective knowledge "the rearing of a child or children, especially the care, love, and guidance given by a parent" [thefreedictionary.com] goes by many names. Under hyper-parenting for instance, go helicopter parents, lawnmower parents, cosseting parent, bulldoze parent. The same base in all of the words - OVERPARENTING AS A PATTERN OF BEHAVIOUR IN THE MODERN WORLD - provides different profiles: the phrase helicopter parent gives access to the knowledge that parents tend to hover around their kids, orchestrate their lives, and prevent them from errors and pain. Within the same base the phrase 
lawnmower parents profiles the idea that overparenting is taken to the next level: that of not hovering over kids, but preparing the way for their children to succeed (=take away every bump along the way); cosseting parent is associated with the idea of coddling a pet; bulldoze parenting represents the so-called "passive-aggressive manner" with which they forge ahead before their kids in order to remove obstacles. Those who are against overprotectiveness and overinvestment of moms and dads introduce slow parenting, simplicity parenting, free-range-parenting. As their base these words evoke the conception of bringing up children that is associated with the idea that it is important to avoid overprotectiveness that leads to negative consequences, such as anxiety and stress, low self-esteem, failure to manage with crisis, etc.

The next examples illustrate that meaning, arising out of the contexts of knowledge, might be activated within more than one domain: two domains overlap contributing their own conceptual content. Particularly, it takes place when participants violate punctuation rules, ignore or avoid the linear structure of written discourse, etc.:

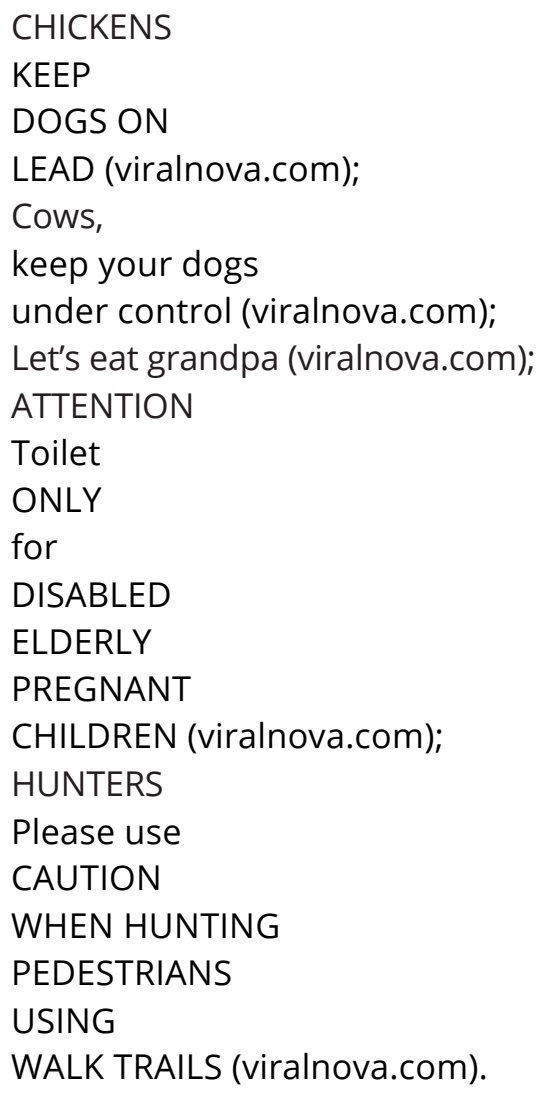

In (24), the intended meaning "to warn dog-keepers of the chickens around and to ask the former to keep their dogs leashed to prevent the latter from chasing those chickens" overlaps within the domain SOMEBODY DOES SOMETHING. The absence 
of the full stop after the word chickens puts the event into the category of an informative discourse rather than imperative. Compare: Chickens. Keep dogs on lead which is imperative and CHICKENS KEEP DOGS ON LEAD which is informative. On the contrary, wrong comma placements are also exceedingly common, as in (25). The statement does not require the comma to serve a logical purpose of addressing cows. The domain which initially the speaker of the English language intended to activate was that of TAKE CARE. Compare: Cows. Keep your dogs under control.

The absence of the comma in (26) modifies the meaning of the statement from "an action-oriented encouragement" (Let's eat, grandpa) with the specified recipient (grandpa) to "an object-oriented invitation" (Let's eat grandpa) with the unknown recipient (it is not clear whom exactly the statement is addressed to).

In (27), the boundaries of a particular category (CHILDREN) are specified: disabled elderly pregnant children. Common sense presumes that such features as 'elderly' and 'pregnant' cannot be ascribed to children. The metaconcept LANGUAGE PERFORMANCE (that the speaker of the English language activates) structures the discourse as instantiating a 'one-category event' (only for disabled elderly pregnant children), although the human experience establishes a variety of categories among people (disabled, elderly, pregnant, etc.) as well as a variety of human beings (toddlers, kids, adults, grown-ups, etc). The function of the (missing) commas in this example - to itemize words - is not preserved. Compare: Attention. Toilet only for disabled, elderly, pregnant, children.

The same pattern of meaning-making is observed in (28). The domain HUNTER'S SEASON is activated by the absence of the full stop to divide the idea into two different parts: the first - advisory (Hunters, please, use caution when hunting) - and the second - informative (Pedestrians use walk trails).

In the next samples, the speaker of the English language relies on the context of sociocultural knowledge and creates the meaning with the context-of-socioculturalknowledge-oriented construal under the metaconcept LANGUAGE PERFORMANCE:

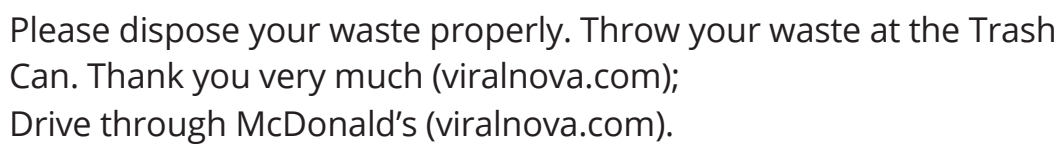

In (29) at implies direction or location (throw at); in / into, which would be more appropriate here and suit the meaning, involve a containment function; in (30) through activates the idea "from one end to another"; the idea should be expressed by round. It is experience, meaningful to human beings by virtue of the so-called embodiment that underpins in / into rather than at; round rather than through as the CONTAINER image schemas that are dynamically re-structured in these examples 
due to the participant's lack of knowledge of the English language. Compare: Please dispose your waste properly. Throw your waste into the Trash Can; Drive (=turn) round McDonald's (because the road is blocked).

The next example illustrates that meaning as well as the choice of language units depend on the knowledge of a variety of factors (the knowledge of the status of the event, its importance, for instance). A social event, especially in someone's house, when people talk, drink, eat, and dance is represented by the word party. However, if somebody is invited to a party, it becomes important to activate a particular context of the knowledge associated either with an entertainment, job or pastime that the participant means: a birthday party; Halloween / Christmas party; surprise party; dinner party; office party; fancy dress party; cocktail party; political party. In the following samples, discourse is semantically dependent on the metaconcept ROLE, which encourages the speaker to specify the event, ascribe some particular meaning to it and choose the lexical unit for it:

- as an informal event with family members:

Shana's picture won first prize, so we had a big family get-together to celebrate (LLA, 2003, p. 845).

In the linguistic example get-together, the selected semantic values (in Evans's terms (2009)) are: "friendly", "informal", "meeting", "enjoyment" that are associated with the speaker's knowledge about the statuses of the guests and the roles they play in life (a mother can perform the role of a close friend; a dad may carry through his responsibility of taking care of the family and providing it with some basic needs, etc.);

- as a party for someone who is leaving the place where they work:

Are you going to Darren's leaving do? (LLA, 2003, p. 845);

A friend of mine is having a bit of a do in town tomorrow night (LLA, 2003, p. 845).

The lexical concepts [DO], [LEAVING DO] provide access to the context of knowledge about parties that are held by speakers of English who live in Great Britain and / or among close relations: the word do is marked as "British spoken" (LLA, 2003, p. 845);

- as a party at which presents are given to a woman who is either getting married or is going to have a baby:

I want to thank both of you again for your beautiful shower gifts (LLA, 2003, p. 845);

We didn't play any of the usual games at the baby shower (LLA, 2003, p. 
845).

The lexical concept [SHOWER] activates the context of knowledge about parties that traditionally are given on special occasions and the domain BIRTH (the birth of a new family or a baby) in the USA; the word shower is specified as "American" (LLA, 2003, p. 845);

- as an informal big party, usually held by celebrities:

The band are flying out to Ibiza tonight for a huge four-day celebrity bash (LLA, 2003, p. 845).

In the next examples, the word restaurant might represent a variety of meanings - a masterpiece or a design / culinary failure, comfort, emotions, etc. - within the contexts of sociocultural knowledge that, in turn, are dependent on the metaconcepts (or clusters of the metaconcepts) ROLE, VALUE and NORM. For an architect, for instance, the focus of attention is on the local tradition, the city elegance and wide aesthetic appeal, or their absence, as in (37):

$$
\begin{aligned}
& \text { We have taught generations of architects to speak out as artists, but we } \\
& \text { haven't taught them how to listen. <... The chief consideration of the } \\
& \text { restaurant crisis appears to be funding and quantity, rather than } \\
& \text { quality, design, the exploration of new solutions and advantages } \\
& \text { (dailymail.co.uk); }
\end{aligned}
$$

for a social urbanist it (some particular restaurant) is oriented to a success with the public:

$<\ldots>$ The second floor of the restaurant is the dining area, designers use dark blue seats and curtains to bring a little bit quiet interior space, so that customers can enjoy a delicious meal at ease here (archdaily.com); Dining out is rarely just about the food. The scene, the socializing, and the sense of a special event are equally important. A simple meal seems that much more appetizing when paired with appealing furniture, luxurious finishes, and alluring lightning (architecturaldigest.com);

for a traveler, passer-by or customer - a place which offers food and comfort:

A NEW restaurant which promises guests authentic Italian dishes in an intimate setting has opened its doors in South Liverpool (thefreelibrary.com); Dear guest, Zest is a self-clear restaurant $<. . .>$ You may be asked to share your table or give preference to guests purchasing food (University of East Anglia); 
for a critic - to express an opinion on a matter involving a judgment of its righteousness, beauty, or technique:

Design tastes of the public are becoming rapidly sophisticated through digital media and communications and I wonder if it is time for people to see this restaurant for what it should be - an expression of technology and aesthetics (David Stewart);

for a child it is associated with a happy or sad experience:

Mum, could we go to the restaurant for a pizza, please? (BNC);

for parents - a variety of meals on the menu:

$$
\begin{aligned}
& \text { The kid's menu keeps growing. The restaurant chain recently added } \\
& \text { three more sides: corn, mandarin oranges, and pineapple to the seven } \\
& \text { options it already had. Entrees range from grilled chicken to pasta to } \\
& \text { pizza (parents.com). }
\end{aligned}
$$

All these meanings (see above) are ascribed by speakers of English who represent different age, social status, or professional groups. The metaconcepts ROLE, NORM, VALUE orient the speakers as to what they should profile in their discourse. This example documents that different contexts of sociocultural knowledge are assumed even where the same language and the same words are used.

Consider the next example that characterizes selection, classification and evaluation as basic processes of interpretation:

- selection as a choice of topic "Drunkenness":

$$
\begin{aligned}
& \text { Drank! }<\ldots>\text { Something chronic }<\ldots>\text {. And always more agreeable when } \\
& \text { he had a drop in }<\ldots . .>\text {. When he was out of work, my mother used to } \\
& \text { give him fourpence and tell him to go out and not come back until he'd } \\
& \text { drunk himself cheerful and loving-like. }<\ldots .>\text { lots of women has to make } \\
& \text { their husbands drunk to make them fit to live with }<\ldots>\text {. If a man has a } \\
& \text { bit of a conscience, it always takes him when he is sober; and then it } \\
& \text { makes him low-spirited. }<\ldots>\text { A drop of booze just takes that off and } \\
& \text { makes him happy (Shaw. Pygmalion. 1994, p. 98). }
\end{aligned}
$$

In the example, the cognitive-discursive interpretant (CDI) mentioned above is represented by the following lexical concepts [BOOZE], [DRUNK] that give access to sociocultural knowledge that reveals Liza's memories of her father who was always drunk. Classification as a cognitive process of interpretation involves categorizations of objects, events, etc. within contexts of sociocultural knowledge that participants activate. The cognitive-discursive interpretant of classification in the example is 
represented by the lexical concept [CHRONIC] which illuminates the idea of 'being sick' (chronic - "lasting for a long period of time or marked by frequent recurrence, as certain diseases" [thefreedictionary.com]). The cognitive-discursive interpretant of evaluation within contexts of sociocultural knowledge represents a variety of meanings on a broad scale of assessment valuation standards. In the example, Liza's assessment of her father's life is represented by the lexical concepts [AGREEABLE], [CHEERFUL], [LOVING-LIKE], [MAKE HAPPY] that highlight her "policy of indulging his tastes and passion" and "approving of his behavior" in general. As a research tool, cognitive-discursive interpretant is a technique that reveals sociocultural discourse specificity, i.e. Liza's subjective construct about relationships among family members.

The interplay between the context of collective knowledge and the context of sociocultural knowledge reflects the correlation of static and dynamic aspects of meaning-making. Consider chronic as a disease within the context of collective knowledge (see above) and chronic which is positively evaluated in Liza's discourse. In other words, the cognitive-discursive interpretant which constitutes selection, classification and evaluation reveals interplay of static and dynamic dimensions of context of sociocultural knowledge.

Consider the next sample that explains what causes the mismatch of two conceptual systems (Mrs. Eynsford Hill's and Liza's):

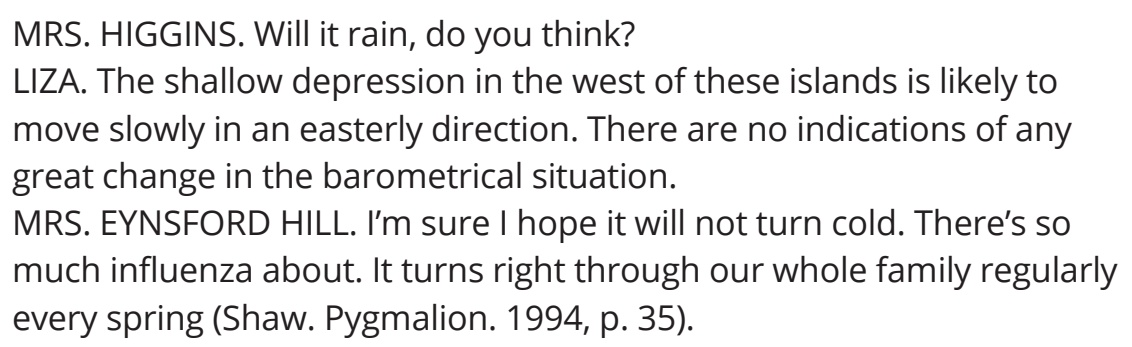

Liza's discourse is dependent on the metaconcept ROLE that represents her as a student studying the English language. Mrs. EYNSFORD HILL's expectations are oriented towards the ROLE of a guest rather than that of a student; she represents the knowledge of informal communication patterns that are appropriate among acquaintances. The meaning that she maintains is revealed by language units: the lexical choice provides a different way of framing a situation, giving rise to the context-of-sociocultural-knowledge-oriented construal that reveals her individual conceptual system.

So, sociocultural knowledge in terms of the metaconcepts determines discourse, language use and meaning construction by virtue of the basic context-ofsociocultural-knowledge-oriented construal which involves selection, classification and 
evaluation as cognitive functions of the human mind.

\section{Conclusions and areas for future research}

There is an extensive and rich theoretical literature that examines the problem of how meaning is created, how language incorporates culture and what role a human being plays in it. Although much progress has been made with the theories and many of the central theoretical predictions of this literature have received substantial empirical support, much remains to be done. The relevance of the fundamental problem of language and mind interrelation, such as the focus on the interpretive function of language in the process of knowledge construction, the specificity of cognition in language processing, the interrelation of linguistics and extralinguistic knowledge in the processes of language representation is still the subject of ongoing research.

The article contains an important contribution to the field of Sociocultural Cognitive Semantics, a framework aimed at understanding sociocultural constraints and opportunities on language use, discourse construction and meaning-making process. The article proves that a full understanding of meaning must include a theoretical account of the factors that provide a convincing theory to explain why individuals are inclined to speak in certain ways and due to what internal/external circumstances. It shows that the information about the outer world is processed and stored in mental structures - the metaconcepts - that are activated in language use and discourse construction. Meaning as a feature of an individual mind is deeply woven into the contexts of knowledge and represents a complex process of contexts correlation (contexts of collective knowledge and contexts of sociocultural knowledge) by virtue of the metaconcepts and the context-of-sociocultural-knowledgeoriented construal.

Despite the considerable advances that have been made, there remain a number of areas for further research. For instance, the necessity to study language as an instrument for cognitive experience construction which is pursued by scientific demand that underlies activities of human mind in the processes of world interpretation by virtue of conceptual linguistic analysis. This perspective reflects two main aspects of human-world interaction: globalization and cultural integration with the focus on "cognition - language - society and culture" intersection.

Another important avenue for further research presupposes the sociocultural specificity of human mind and language as a semiotic system representing mentality of its speakers, as well as intercultural dialogue among people with different cultural backgrounds. Contemporary scientific research in many branches of science is 
dependent on the results of the study of human mind, its role in decision-making processes, scientific included, and language as the particularly exclusive access to it.

Finally, the approach undertaken to language as an interpretive tool gives insights into the problem of meaning as a dynamic experience construction process represented by virtue of language within multiple networks of human knowledge and language use.

In summary, Sociocultural Cognitive Semantics is capable of achieving significant results in the area of language use and (sociocultural) meaning. The approach invites collaboration between linguists, sociologists, discourse analytics, interpreters among others to study how human beings are represented in language use and what mental processes are involved in it.

The results are expected to initiate scientific research in the fields of language teaching, language learning and linguistics. They are to present new findings to language and thought theory, theory of language world view and interpretation and elaborate on theoretical assumptions in language structure and language functions, as well as grammatical and lexicographical descriptions of language, language teaching methods and speech and language therapy.

\section{About the author}

Nikolay N. Boldyrev is Honoured Scholar of the Russian Federation, Professor and Director of the Center for Cognitive Research at Derzhavin Tambov State University. Nikolay Boldyrev has been developing the theory of Linguistic Anthropocentricity on a holistic methodological basis. He currently coordinates the Russian Cognitive Linguists Association and is the Editor-in-Chief of Issues of Cognitive Linguistics journal.

Olga G. Dubrovskaya is an Assistant Professor at Tyumen State University. Her research interests include cognitive linguistics, discourse analysis and intercultural communication.

Irina N. Tolmacheva, PhD in Philology, does her cognitive research at Derzhavin Tambov State University. She focuses on the anthropocentric nature of linguistic phenomena within the framework of cognitive approach. 


\section{Acknowledgements}

This work is supported by research grant 15-18-10006 "A cognitive study of anthropocentric nature of language" of the Russian Science Foundation at Derzhavin Tambov State University.

\section{Article history}

Paper received: 13 February 2017

Paper received in revised form and accepted for publication: 27 April 2017

\section{References}

Boldyrev N.N. (2015). Antropotsentricheskaya sushchnost' yazyka v ego funktsiyakh, edinitsakh, kategoriyakh. Voprosy kognitivnoy lingvistiki, 1, 5-12. [Antropocentric nature of language in its functions, units, and categories].

Boldyrev, N. N. \& Dubrovskaya, O.G. (2016). Sociocultural commitment of Cognitive Linguistics via dimensions of context. ILHA DO DESTERRO. A Journal of English Language, Literatures in English and Cultural Studies, 69 (1), 173-182.

Boldyrev, N. N. \& Dubrovskaya, O. G. (2016). Sotsiokulturniy kontekst interpretatsii mira i formirovaniya diskursa. Izvestiya RAN. Seriya literaturyi i yazyka, 75(1), 29-39 [Sociocultural context of world interpretation and discourse construction].

BNC - British National Corpus <http://www.natcorp.ox.ac.uk> [22/11/2016].

Chomsky, N. (1986). Knowledge of language: Its nature, origin, and use. New York: Praeger.

Croft, W. (2009). Toward a social cognitive linguistics. In V. Evans \& S. Pourcel (Eds.), New Directions in Cognitive Linguistics (pp. 395-420). Amsterdam: John Benjamins.

Demyankov, V.Z. (1994). Kognitivnaya lingvistika kak raznovidnost interpretiruyuschego podhoda. Voprosy yazykoznaniya, 4, 17-33 [Interpretive aspect of Cognitive Linguistics].

Evans, V. (2009). How words mean: lexical concepts, cognitive models, and meaning construction. Oxford: Oxford University Press.

Evans, V. \& Green, M. (2006). Cognitive Linguistics: An introduction. Edinburg: Edinburg University Press.

Geeraerts, D. (2010). Theories of Lexical Semantics. Oxford: Oxford University Press.

Geeraerts, D. (2016). The sociosemiotic commitment. Cognitive Linguistics, 27(4), 527-542. 
Harder, P. (2010). Meaning in mind and society: A functional contribution to the social turn in Cognitive Linguistics. Berlin: Mouton De Gruyter.

Hart, C. (2010). Critical discourse analysis and cognitive science: new perspectives on immigration discourse. Palgrave: MacMillan.

Kubryakova, E. S. (2004). Yazyk i znanie: Na puti polucheniya znaniy o yazyke: Chasti rechi s kognitivnoy tochki zreniya. Rol yazyka $v$ poznanii mira. M.: Yazyki slavyanskoy kultury [Language and Knowledge: On how to acquire knowledge about language: Parts of speech in the framework of Cognitive Linguistics: The role of language in the process of world conceptualization].

Lakoff, G. \& Johnson, M. (1999). Philosophy in the flesh: The embodied mind and its challenge to western thought. New York: Basic Books.

Langacker, R. W. (2000). Grammar and conceptualization. Berlin; New York: Mouton De Gruyter.

Langacker, R. W. (2008). Cognitive Grammar: A basic introduction. Oxford: Oxford University Press.

LLA (2003) - Longman Language Activator. Helps you write and speak natural English. Longman.

Pütz, M., Robinson, J. A. \& Reif, M. (eds.) (2014). Cognitive Sociolinguistics. Social and cultural variation in cognition and language use. Amsterdam/Philadelphia: John Benjamins Publishing Company.

Shaw, G. B. (1994). Pygmalion. New York: Dover Publications.

Tomasello, M. (1999). The cultural origins of human cognition. Cambridge: Harvard University Press.

Vygotsky, L. S. (1986). Thought and language. Cambridge, Massachusetts: The MIT Press. 